\title{
REFERÊNCIA E DENOTAÇÃO: DUAS FUNÇÕES SEMÂNTICAS IRREDUTÍVEIS ${ }^{1}$
}

\author{
Adriana Silva Graça \\ Universidade de Lisboa
}

\section{INTRODUÇÃO}

Neste ensaio pretende-se mostrar que nomes próprios e descrições definidas executam funções semânticas distintas e mutuamente irredutíveis. Isto quer dizer que, mais especificamente, se obtém a seguinte conjunção de teses, as quais vamos desenvolver nas duas partes centrais ( 2 e 3$)$ que constituem o ensaio:

Descrições definidas não são nomes.

Nomes não são descrições definidas.

Designe-se a primeira destas teses por Tese A e a segunda por Tese B. Então o aspecto inovador deste ensaio consiste em filiar ambas as teses A e $\mathrm{B}$, em conjunto, no pensamento de Bertrand Russell, em especial esta última, da forma que a seguir se passa a especificar.

Note-se que na literatura filosófica contemporânea a defesa da tese A, que elimina a possibilidade de descrições definidas alguma vez poderem ser caracterizadas de modo diferente do que por meio da Teoria das Descrições Definidas, não está normalmente associada à defesa da tese $\mathrm{B}$ mas sim à defesa da sua negação. Isto significa que, em geral, quem defende a tese A adopta também o ponto de vista segundo o qual nomes são descrições definidas abreviadas e logo, para todos os efeitos, analisáveis de novo por

\footnotetext{
${ }^{1}$ Pode ser encontrada uma expansão da maioria dos argumentos contidos neste ensaio na minha dissertação de doutoramento, submetida à Universidade de Lisboa, intitulada Referência e Denotação. Um Ensaio acerca do Sentido e da Referência de Nomes e Descrições (2000). Estou grata ao Professor Manuel Lourenço, meu orientador da dissertação, e à direcção da Disputatio.
} 
meio da Teoria das Descrições Definidas. A ideia segundo a qual nomes e descrições definidas têm uma única função semântica, em particular a que é elucidada pelo sentido do quantificador existencial, é explicitamente rejeitada neste ensaio.

A defesa conjunta das teses $\mathrm{A}$ e $\mathrm{B}$, e a sua filiação no pensamento de Bertrand Russell, exige assim um trabalho de construção de uma interpretação forte e de uma interpretação fraca das suas doutrinas, de modo a acomodar ambos os resultados visados:

i) A interpretação forte, de acordo com a qual a função semântica de descrever ou denotar é elucidada à custa da análise proporcionada pela Teoria das Descrições Definidas que permite explicar todos os usos semanticamente relevantes de proposições que contêm descrições definidas,

ii) a interpretação fraca, de acordo com a qual é necessário que existam termos genuinamente referenciais, como limite da análise lógica da linguagem, relativamente aos quais o seu sentido depende do objecto que referem (e dos quais são representantes no mundo linguístico), que permite sustentar que os nomes próprios da linguagem corrente, em geral, são os candidatos naturais a executar a função semântica de referir.

É interessante notar a seguinte assimetria entre as teses A e B. A Tese A, segundo a qual descrições definidas não são nomes, é para ser entendida como uma proposição universal negativa, ou seja, é para ser entendida como refutando a ideia segundo a qual existem usos supostamente referenciais semanticamente relevantes de descrições definidas. Esta tese representa assim uma defesa da ideia segundo a qual a Teoria das Descrições Definidas elucida correctamente o comportamento semântico deste tipo de expressões. A Tese B, segundo a qual nomes não são descrições definidas, assimetricamente, é para ser entendida como uma proposição particular negativa. Mais especificamente, é para ser entendida como significando que a esmagadora maioria dos nomes não são descrições definidas abreviadas e como refutando a ideia segundo a qual todos os nomes são descrições definidas. A Tese B, ao contrário da Tese A, admite assim excepções, ou seja, admite a ideia segundo a qual alguns nomes são descritivos.

Nas partes 2 e 3 deste ensaio vão ser consideradas, respectivamente, a Tese A e a Tese B. Como corolário do que fica dito segue-se que a defesa da Tese B exige a construção de uma alternativa, ao contrário da defesa da Tese A. Com efeito, para esta última já se está na posse da Teoria das Descrições Definidas, restando unicamente ter que resolver o problema de como expli- 
car a ideia intuitiva segundo a qual há usos genuinamente referenciais de descrições definidas. Ao contrário, no que diz respeito à Tese $\mathrm{B}$, é necessário proceder-se à construção de uma alternativa. Em particular, é preciso saber como explicar quer o sentido quer a referência de nomes próprios, se nem o primeiro nem a segunda podem em geral ser elucidados à custa daquilo que explica quer o sentido quer a forma pela qual referem as descrições definidas (que supostamente seriam abreviadas pelos nomes).

\section{DESCRIÇÕES DEFINIDAS NÃO SÃO NOMES}

A «interpretação forte» da filosofia russelliana é extraída daquilo que é normalmente considerado como a herança filosófica que Russell deixou. Ela resulta de fundir num todo coerente aspectos lógico-semânticos e aspectos epistemológicos da sua filosofia, de tal maneira que o seguinte resultado obtém:

Apreender o sentido de um termo simples corresponde precisamente ao conhecimento directo ou por contacto da entidade que o termo representa no mundo linguístico, $\log o$ as descrições definidas e os nomes próprios da linguagem corrente (que normalmente as abreviam) - i.e., todos os termos que na gramática de superfície são considerados termos singulares - não o são de facto, não são termos simples, uma vez que não representam entidades conhecíveis directamente ou por contacto.

$\mathrm{Na}$ «interpretação forte» fica-se com a ideia de que a Teoria das Descrições Definidas é necessária e suficiente para explicar todos os usos semanticamente relevantes deste tipo de expressões e dispensa-se a ideia de que os nomes da linguagem corrente são descrições definidas abreviadas. Se esta ideia não fosse dispensada, não seria possível filiar em Bertrand Russell a irredutibilidade das duas funções semânticas que nos ocupam.

A descoberta filosófica crucial feita em "On Denoting" consiste em mostrar que, contra todas as aparências em sentido contrário, os termos descritivos não são genuinamente referenciais. Ao contrário do que Frege tinha concluído, Russell mostra que a forma como os termos descritivos têm sentido é diferente da forma como termos genuinamente referenciais o têm, não podendo assim aqueles ser considerados como um subconjunto destes últimos. Russell introduz assim uma clivagem dentro de uma categoria aparentemente uniforme de termos, sendo este o resultado que nos interessa para defender a Tese A, a saber, descrições definidas não são nomes.

${ }^{2}$ Cf. B. Russell (1905). 
Resumidamente, qual é a diferença entre um nome próprio genuíno «a» e uma descrição definida «o $F »$ ? Enquanto «a» é um mero representante linguístico de um átomo físico (para Russell, um sense datum), donde se segue que «a» não pode ser vazio, que «a» tem sentido isoladamente e que o sentido de «a» coincide com o objecto extralinguístico que representa, «o F» identifica o objecto que putativamente denota por meio de uma propriedade contida na descrição, a propriedade $F$, donde se segue que «o $F$ » pode não denotar qualquer entidade sem que com isso perca sentido, que «o $F »$ não tem sentido isoladamente mas sim no contexto de uma proposição e que o sentido de «o F é G» é dado pela tripla condição de i) «o F» ser satisfeito por um indivíduo, ii) por não mais do que um indivíduo e iii) esse indivíduo ter também a propriedade G. A frase «a é G» exprime um pensamento que depende da identidade do objecto representado por «a», é objectodependente, ao contrário da frase «o $\mathrm{F}$ é $\mathrm{G} »$ que exprime um pensamento independente da identidade do objecto que satisfaz a descrição definida «o $\mathrm{F} \gg^{3}$.

Uma descrição definida é um termo quantificacional, cujo sentido pode ser elucidado à luz dos mesmos princípios do que qualquer outro termo desta natureza (símbolo incompleto), ao passo que um nome esgota o seu sentido no objecto que representa. Por meio de um certo uso de um nome tem-se um acesso imediato e directo ao objecto, enquanto que por meio de um certo uso de uma descrição definida se tem um acesso mediado pelos predicados nela contidos e logo um acesso indirecto ao objecto através de certas propriedades que ele tem. $\mathrm{E}$ isto acontece mesmo naqueles casos em que a descrição definida é univocamente satisfeita, o que leva Russell a concluir que, dado que nomes genuínos e descrições definidas têm o sentido elucidado de forma distinta, então estas duas categorias de termos são irredutíveis.

Russell, de forma sugestiva e como corolário dos resultados que acabámos sucintamente de apresentar, defende em "On Denoting" e no seu trabalho filosófico subsequente que a nomes próprios genuínos e a termos descritivos estão na verdade associadas duas funções semânticas distintas, a de referir e a de denotar, respectivamente. Esta tese é na verdade resultante da sua descoberta segundo a qual a relação semântica que existe entre um nome e o objecto do qual é representante é de natureza essencialmente diferente da relação semântica que existe entre um termo descritivo e o objecto que ele identifica (mesmo no caso em que este objecto existe e é único). No primeiro caso temos uma relação directa e imediata, no segundo uma relação

\footnotetext{
${ }^{3}$ Cf. S. Neale (1990), pgs. 15-19.
} 
indirecta e mediata, na qual um certo objecto é identificado por meio da satisfação de certos predicados.

Este ponto crucial que Bertrand Russell apresentou conduz-nos ao resultado visado na Tese A: descrições definidas não são nomes. Basicamente, aceitamos como procedente o argumento de Russell. Mas foi argumentado ${ }^{4}$, contra este resultado, que existem usos genuinamente referenciais de descrições definidas. Não constituem estes usos contra exemplos à Tese A, a qual é para ser considerada como universal?

Considere-se em primeiro lugar o argumento de Donnellan a favor da ideia de que existem usos genuinamente referenciais de descrições definidas. Este argumento é apresentado sob a forma de dois casos contrastantes nos quais se executam dois usos possíveis de uma mesma frase que contém um termo descritivo. Tome-se a frase «o assassino de Smith é tarado» usada em dois cenários diferentes, o cenário $(\mathrm{A})$ e o cenário $(\mathrm{B})^{5}$. O cenário $(\mathrm{A})$ é o seguinte: Smith é uma pessoa adorável. É encontrada bárbara e brutalmente assassinada e, nesta situação, alguém que conhece Smith, quando se depara com o corpo, diz consternado: «o assassino de Smith é tarado». O cenário (B) é o seguinte: Jones está no tribunal a ser julgado pelo homicídio de Smith, não se sabendo ainda se ele é ou não culpado. Dado o comportamento estranho e bizarro de Jones no tribunal, alguém que assiste ao julgamento exclama então: «o assassino de Smith é tarado».

Na base de casos como este, Donnellan propõe uma diferença entre o uso referencial e o uso atributivo de uma descrição definida e argumenta que só no uso atributivo de uma descrição é que esta se comporta tal como a Teoria das Descrições Definidas de Russell elucida e prevê. No seu uso referencial, a descrição definida comporta-se como um nome genuinamente referencial. O cenário (A) ilustra o uso atributivo; o (B), o uso referencial. Com efeito, no cenário (A), a asserção feita por meio do uso da fase «o assassino de Smith é tarado» é, não acerca de um certo indivíduo específico, mas sim acerca de quem quer que seja que satisfaz o atributo contido na descrição «o assassino de Smith». Ao contrário, a asserção feita por meio do uso da mesma frase, no cenário (B), é acerca de um indivíduo específico, aquele que está a ser julgado em tribunal, não sendo de forma alguma necessário, para a identificação desse indivíduo, o facto de o atributo contido na descrição ser safisfeito. Na verdade, mesmo que aquele que está a ser julgado não seja o assassino de Smith, a descrição cumpre o seu papel, o de identificar Jones. No cenário (A), a asserção só pode ser verdadeira do indivíduo que

\footnotetext{
${ }^{4}$ Cf. K. Donnellan (1966).

${ }^{5}$ Cf. Ibidem, pgs. 176, 177.
} 
de facto assassinou Smith, no (B), a frase pode ser verdadeira mesmo que não tenha sido Jones a assassinar Smith.

Generalizando, podemos dizer que no uso atributivo da descrição definida «o $F »$ em «o $F$ é $G »$, se nada corresponde a «o $F »$, então não é dito acerca de um qualquer hipotético objecto que ele é G. No uso referencial de «o F» em «o F é G», se nada corresponde a «o F» (se não for possível encontrar o único objecto que satisfaz F), é ainda considerado ter sido dito acerca de um objecto específico que ele é $\mathrm{G}$.

De facto Donnellan distingue entre duas funções semânticas distintas, a de referir e a de denotar (que de resto, tal como ele próprio reconhece, é uma distinção de Russell), mas agora aplicando-a exclusivamente a termos descritivos, para demonstrar que estes podem executar ambas as funções. A função referencial que para Russell era um exclusivo de termos simples, genuinamente referenciais, os quais eram vistos como meros representantes linguísticos de objectos extralinguísticos - os seus nomes logicamente próprios - pode ser executada, em algumas circunstâncias, segundo Donnellan, por descrições definidas. No cenário (B), de facto, a descrição «o F» é um mero mecanismo que permite identificar a referência, Jones, sendo absolutamente inessencial para proceder à identificação o facto de Jones ter na verdade sido o assassino de Smith.

Regressamos agora à nossa questão. Constituem exemplos como este um problema para a defesa da nossa Tese A? Não podem afinal, em certos usos, descrições definidas funcionar como nomes? A saída possível para este problema, do nosso ponto de vista, não está em descartar a importância deste tipo de exemplos. Os exemplos são suficientemente importantes para terem que ser elucidados. A saída possível resulta assim de nos perguntarmos como é que de todo a descrição definida «o F» identifica um indivíduo em circunstâncias nas quais a descrição definida não é por ele satisfeita. A resposta é a seguinte. Não é de facto a proposição que é expressa que permite proceder à identificação de um e um único indivíduo, mas é sim a proposição intencionada pelo utente da frase que o permite fazer ${ }^{7}$. Só deste modo se pode explicar que, no caso do cenário (B), Jones possa ser identificado, quer seja quer não seja o assassino de Smith, por meio da descrição definida «o assassino de Smith». Ele é em todo o caso identificado porque, independentemente de ser ele ou não quem matou Smith, era acerca dele que o utente da frase queria ou tinha intenção de falar. Mas, se assim é, então este tipo de casos são relevantes não semântica mas sim pragmaticamente: é

\footnotetext{
${ }^{6}$ Cf. Ibidem, pg. 173.

${ }^{7}$ A diferença entre proposição expressa e proposição intencionada foi explorada por H.P. Grice (1969) e por S. Kripke (1979).
} 
a proposição intencionada pelo utente da frase e não aquela que é de facto expressa que torna o hipotético uso referencial de uma descrição definida inteligível.

Relativamente àquilo que fica por esclarecer aceitando a Tese $\mathrm{A}$, em particular como explicar a intuição segundo a qual existem usos genuinamente referenciais de descrições definidas, ela é facilmente elucidada com a distinção entre proposição expressa por um certo uso de uma frase e proposição intencionada por esse mesmo uso. O que efectivamente ocorre nos hipotéticos usos referenciais de descrições definidas é uma não coincidência entre estas duas proposições.

A esta luz, é a proposição intencionada e não aquela que é de facto expressa que torna o uso referencial inteligível e, assim sendo, os usos referenciais de descrições definidas tornam-se semanticamente irrelevantes. Entendendo a referência como fenómeno semântico, e não como fenómeno de ordem pragmática, é assim descartada esta intuição sem qualquer dificuldade. Efectivamente, só a proposição intencionada pelo utente, e não aquela que é na realidade por ele expressa, pode alguma vez tornar verdadeiro um certo uso de uma frase no qual a descrição definida que está hipoteticamente a identificar um objecto nem sequer é por ele satisfeita.

Isto deixa-nos na conclusão segundo a qual a Teoria das Descrições Definidas é necessária e suficiente para explicar todos os usos semanticamente relevantes de termos descritivos, pelo que eles nunca podem ser considerados nomes ou termos genuinamente referenciais. A distinção semântica russelliana, atrás apresentada, entre referir e denotar, elucida o nosso ponto: mesmo quando uma descrição definida identifica univocamente um objecto, o processo que, por meio do seu uso, permite a identificação do objecto é distinto do processo que permite identificar um objecto por meio do uso de um nome. No primeiro caso, a identificação é feita pela verificação da satisfação unívoca dos predicados contidos na descrição, no segundo, ela é feita directamente. A Tese A é então aceite como completamente procedente.

\section{NOMES NÃO SÃO DESCRIÇÕES DEFINIDAS}

A «interpretação fraca» da filosofia russelliana é extraída do seguinte resultado que Bertrand Russell defendeu e que foi relativamente negligenciado pela tradição filosófica:

Apreender o sentido de um termo simples corresponde precisamente ao conhecimento directo ou por contacto da entidade que o termo representa no mundo linguístico; logo, é necessário que exista um limite para a análise lógica das pro- 
posições, no qual são encontrados os termos simples, ou átomos linguísticos, que as constituem, os quais são genuinamente referenciais e para os quais o seu sentido coincide com o próprio objecto referido.

A ideia básica de Russell à qual fazemos apelo, para na sua base se defender que nomes não são descrições definidas, é a ideia segundo a qual é necessário que existam termos genuinamente referenciais. Trazemos então de Russell, nesta interpretação a que chamamos fraca da sua teoria, primariamente, a tese de que, no limite, é necessário que existam termos simples, cujo sentido consiste no objecto que estes termos representam no mundo linguístico. Os termos genuinamente referenciais executam a função semântica de referir, a qual é irredutível a qualquer outro género de função semântica, nomeadamente à função descritiva ou denotativa.

Consideramos como sendo de importância relativamente menor a tese, que Russell também defendeu, segundo a qual aquilo que tomamos normalmente como nomes próprios não o são de facto visto, segundo ele, debaixo de análise eles não resistirem, i.e., eles se revelarem ser não mais de que expressões denotativas ou descritivas camufladas. A importância desta tese é, em relação à tese anterior, menor, dado que independentemente do facto ela ser ou não ser verdadeira, ou seja, independentemente de quais considerarmos serem os termos simples da nossa linguagem - se são os nomes próprios tais como normalmente usados, se são os nomes logicamente próprios de Russell, ou se são quaisquer outros que a investigação filosófica proponha - a intuição básica do pensamento de Russell deve ser mantida. Esta intuição, que julgamos desejável conservar, é a de que o fenómeno semântico que consiste em referir directamente algo no mundo extralinguístico existe, não é redutível a qualquer outro, e é o fenómeno semântico primitivo e mais básico de qualquer linguagem.

A tese segundo a qual os nomes próprios da linguagem corrente são descrições definidas disfarçadas, por nós rejeitada, corresponde na literatura filosófica àquilo que é conhecido por Teoria Descritivista dos Nomes ${ }^{8}$. Efectivamente, para quem aceita que nomes são descrições disfarçadas, é a Teoria das Decrições Definidas que está na base da explicação de como é que nomes têm sentido (genericamente falando): eles têm sentido porque ao seu uso está associado um Sinn fregeano, um modo de apresentação do

\footnotetext{
${ }^{8}$ Sobre a refutação do Descritivismo, $c f$., na minha dissertação de doutoramento, Referência e Denotação, os parágrafos 8 a 11. Basicamente, os argumentos que refutam semanticamente o Descritivismo são baseados no facto de esta teoria não dar conta dos inúmeros casos nos quais a descrição definida, ou Sinn associado a um certo uso de um nome, corresponde a informação falsa (erro) ou incompleta (ignorância) do objecto que, em todo o caso, não deixa de ser a referência do nome.
} 
objecto, o qual consiste na verdade na descrição definida por meio da qual é possível identificar quer o conteúdo conceptual do nome quer o objecto que é a sua referência. Em particular, note-se que o Descritivismo responde com um único conceito - o conceito de Sinn, de Frege (interpretado como sendo um conjunto de predicados atribuíveis com verdade ao objecto referido pelo nome) a três problemas de ordem diferente ${ }^{9}$ : i) o problema de saber como pode ser identificado o conteúdo conceptual do nome, o qual é encarado como correspondendo ao seu Sinn; ii) o problema de saber como é possível identificar a referência do nome, a qual é vista como correspondendo à informação contida naquele conteúdo e iii) o problema de caracterizar a que é que corresponde o uso competente do nome, o qual é visto como decorrendo do facto de a compreensão do nome corresponder à apreensão individual do seu Sinn.

A importância secundária que damos à tese russelliana segundo a qual os nomes que usamos na linguagem corrente são na verdade descrições definidas disfaçadas permite-nos defender sem contradição a ideia de que estes nomes são os candidatos naturais a preencher a função genuinamente referencial que deve ser preservada, e assim podemos, em Russell, filiar a tese segundo a qual nomes não são descrições definidas, a nossa Tese B. O aspecto essencial que permite evitar a contradição é reconhecer que a sua tese principal é, como vimos, a tese segundo a qual a função semântica genuinamente referencial não é eliminável.

O desenvolvimento da «interpretação fraca» da filosofia russelliana e a sua utilização como suporte conceptual para a defesa da Tese B (segundo a qual nomes não são descrições definidas), bem como para a construção de uma alternativa ao Descritivismo, é assim um dos aspectos interessantes deste ensaio. Note-se que, em relação à interpretação fraca do pensamento de Russell, também se fica com uma parte e se dispensa outra. Retém-se a ideia fulcral de que nomes genuinamente próprios não são nem podem ser descrições definidas abreviadas, i.e., de que é necessário assegurar que alguns termos — os nomes próprios genuínos, sejam eles quais forem tenham uma função semântica específica, a de referir (este é o resultado com o qual se fica). Mas, apesar desta função semântica ser objecto dependente, ela não é para ser encarada como coincidindo com o próprio objecto (este é

\footnotetext{
${ }^{9}$ Cf., a este propósito, M. Devitt e K. Sterelny (1987), pg. 40. Repare-se ainda que nunca nenhum defensor da Teoria Descritivista para nomes apresentou desta forma distinta os três tipos de respostas, apesar de elas estarem sempre presentes, de forma indistinta, quer em Frege, quer em Russell (naquela parte do sua doutrina que nós não aceitamos), quer em Searle (um dos principais representantes do Descritivismo nas duas últimas décadas).
} 
o resultado que se dispensa). O sentido de um nome não consiste assim exclusivamente no objecto por ele referido.

Aceitar a Tese B, e defender a ideia de que os nomes próprios da linguagem corrente são os candidatos naturais a ocupar o lugar daqueles termos que são genuinamente referenciais, significa então ter que encontrar uma teoria que sirva para explicar tudo o que era explicado através da Teoria das Descrições Definidas, se se supusesse que nomes próprios eram descrições definidas abreviadas. A alternativa a oferecer tem que ser composta por duas partes: uma, relativa à Teoria da Referência e outra, relativa à Teoria do Sentido. A primeira é para ser encarada como constituindo a base da alternativa, a segunda, como uma extensão da primeira. Passamos então à discussão de cada uma separadamente.

\section{A. TEORIA DA REFERÊNCIA}

O problema que temos então que encarar é o seguinte: como explicar que um certo uso de um nome refira o objecto que realmente refere, se a função semântica de um nome é genuinamente referencial, não denotativa, e, logo, se a esta pergunta não se pode responder com uma frase do tipo: "o nome refere o objecto que refere por este ser o objecto que satisfaz o conjunto de predicados que são apreendidos pelo utente do nome e que correspondem ao seu Sinn"? Esta é a resposta tipicamente descritivista. A nova resposta a dar elucida o fenómeno da referência de um certo uso de um nome em termos, não das condições internas do sujeito, mas da existência de uma relação causal que lhe é externa, entre um certo uso do nome e o objecto que é causa desse uso e que lhe está, mesmo que longinquamente, na origem. Esta é a resposta de tipo causal, que queremos agora desenvolver.

Os proponentes da Teoria Causal da Referência ${ }^{10}$ vêm chamar a atenção para o facto de o contacto com o objecto ser um elemento determinante para a fixação da referência de um nome. A preocupação daqueles que defendem esta teoria deve ser, neste ponto, reconduzida à preocupação que Bertrand Russell teve em assegurar uma explicação para o problema de saber como é que a referência dos termos (que fazem parte de proposições completamente analisadas) é fixada ${ }^{11}$. Para Russell, um nome logicamente próprio (e qualquer termo simples) vê o seu sentido elucidado através do objecto que representa no mundo linguístico e o seu Principle of Acquaintance exige que para que uma proposição seja compreendida tenha que existir conhecimento

\footnotetext{
${ }^{10}$ S. Kripke, K. Donnellan e H. Putnam, entre outros.

${ }^{11}$ Cf. M. Devitt (1989), pg. 212.
} 
por contacto de todos os seus constituintes ${ }^{12}$. Por meio deste Princípio, Russell explica o género de relação que tem que existir entre um termo (genuinamente referencial) e o objecto por ele referido ${ }^{13}$, tendo este último um papel fundamental na caracterização do fenómeno da referência: não há referência sem objecto, não há nomes vazios, i.e., não há nomes logicamente próprios sem portadores, e uma proposição que contenha um termo genuinamente referencial é, como vimos, objecto-dependente ${ }^{14}$.

Compreender um nome, para Russell, é "estar em contacto com o particular do qual ele é nome e saber que ele é um nome desse particular" "15, ou seja, o uso competente de um qualquer termo simples requer sempre uma relação com o objecto extralinguístico que ele é suposto representar na linguagem. Uma teoria que siga o paradigma causal, e não o paradigma descritivista, na procura de uma solução para o problema da fixação da referência, e que estenda a todos os nomes próprios os resultados que Russell obteve para os nomes logicamente próprios, é assim uma teoria de inspiração russelliana.

Numa solução para o problema da fixação da referência de tipo causal, o objecto é considerado como sendo a causa (a fonte ou a origem) de o nome ter uma referência. Mas, dado que os usos subsequentes (em relação aos primeiros usos) desse nome não nos relacionam directamente com o objecto referido por meio desses usos, a referência de um termo é assim para ser explicada à custa de uma cadeia causal apropriada que relaciona indirectamente um certo uso do termo com o objecto por ele referido. A ideia é que os nossos usos de um nome dependem de usos anteriores, e estes, por sua vez, de outros usos anteriores, até chegarmos a um ponto em que se encontram os primeiros usos do nome, os quais ocorrem na presença do objecto, e que assim relaciona directamente o nome com o seu portador.

É assim que o nome refere não por se estar na posse de qualquer conhecimento identificador do objecto, o qual pode ser errado ou insuficiente, mas sim em virtude da existência daquela cadeia causal, constituída pelos diversos usos de um nome, que recua até aos seus primeiros usos, os quais por

\footnotetext{
${ }^{12}$ Constituintes são termos simples, resíduos da análise lógica da linguagem. Um termo descritivo não é um constituinte de uma proposição pelas razões já apresentadas: quando analisado no contexto de uma proposição, a aparente unidade desfaz-se num conjunto do predicados (nomes de universais ou termos gerais) os quais são ditos ser satisfeitos de pelo menos e no máximo um objecto.

${ }^{13} \mathrm{Um}$ termo genuinamente referencial refere, estritamente falando,não um objecto físico mas sim um sense datum. Este aspecto da filosofia russelliana está fora do alcance deste ensaio. Cf. B. Russell (1956).

${ }^{14} \mathrm{Cf}$. acima, pgs. 4 e 5.

${ }^{15}$ Cf. B. Russell (1918), pg. 205.
} 
seu turno fazem a relação do nome com o objecto. Qualquer teoria de tipo causal tem assim duas partes: i) uma primeira, que versa sobre a determinação propriamente dita da referência do nome, relativa aos primeiros usos, e ii) uma segunda, que versa sobre o mecanismo que torna possível o empréstimo da referência, de falante para falante da língua, relativa aos usos subsequentes. $\mathrm{O}$ objecto ele próprio, por um lado, e o carácter eminentemente social da linguagem ${ }^{16}$, por outro, explicam assim o fenómeno de fixação da referência.

O grande problema que o modelo causal tem que enfrentar é o da insuficiência da cadeia causal, para explicar o fenómeno de referência. A questão é que, se ela é necessária (não há referência a objectos sem uma cadeia causal apropriada que relacione o uso de um nome com o objecto que está na sua base), não é no entanto suficiente (podemos estar na posse da cadeia causal apropriada sem, no entanto, com um certo uso do nome, referir o objecto que está na base da cadeia). Este problema ocorre em casos nos quais, em algum ponto da cadeia causal que relaciona os diferentes usos do termo, se dá uma alteração no objecto referido (associada a uma incompreensão por parte de alguém), passando os usos subsequentes do termo a designar outro objecto ${ }^{17}$.

Devitt explica este tipo de fenómeno dizendo que, nesse caso, ocorre uma nova "ancoragem" do uso do termo noutro objecto, dando-se lugar a uma nova cadeia causal, resultando assim a confortável conclusão de que a cadeia causal é suficiente, além de ser necessária ${ }^{18}$. Mas, para além deste resultado parecer uma manobra para salvar a todo o custo a suficiência da cadeia causal para explicar todos os usos de um certo termo, é claramente muito contra-intuitivo defender-se que, nos casos de mudança de referência, se cria uma nova cadeia causal. Basta notar que o novo utente do termo o importou (por assim dizer) a partir de um uso anterior, não tendo havido quebra na cadeia causal, apesar de a essa passagem estar associado um equívoco na identificação do objecto. A mudança de referência mostra, a nosso ver, que o correcto uso do termo deve manter, a todo o tempo, algum tipo de contacto com o objecto referido, sendo que, se isso não for garantido, é possível um certo uso de um termo ser meramente «papagueado» por alguém e não ser efectivamente compreendido.

A solução para o problema da insuficiência da cadeia causal, para explicar que determinados usos de um termo refiram o objecto que está na base

\footnotetext{
${ }^{16}$ Cf. H. Putnam (1975), pgs. 245-252. Putnam elucida particularmente bem este fenómeno com o seu Princípio da Divisão Universal do Trabalho Linguístico.

${ }^{17}$ Cf. G. Evans (1973), caso 'Madagáscar'.

${ }^{18}$ Cf. M. Devitt (1987), pgs. 75, 76.
} 
cadeia, está então em aceitar a insuficiência e concluir que é preciso complementar a explicação de tipo causal com mais alguma coisa. Uma resposta possível, resposta essa que se inspira ainda em Bertrand Russell, é aplicar o seu Principle of Acquaintance a todos os usos do termo e não só aos primeiros usos: para usar competentemente o termo é preciso saber algo acerca do objecto por ele referido, é necessário ter acerca dele alguma informação, a qual tem também que "passar" ou "ser transmitida" de elo em elo da cadeia.

A informação acerca do objecto que está associada ao uso do termo não deve no entanto ser (de novo) entendida como a descrição definida que o utente do termo associa com o objecto por ele referido e que faz com que se possa identificar a referência do nome, o que corresponderia à tese descritivista. Deve antes ser entendida como podendo conter crenças falsas ou podendo ser incompleta, para evitar os problemas da ignorância e do erro, postos ao ponto de vista descritivista. A informação acerca do objecto é aquilo que numa comunidade linguística está ao dispôr acerca do objecto.

Resumindo, temos então o seguinte. Ao contrário de uma Teoria Descritivista dos nomes, a nova teoria, enquanto teoria da referência, explica a capacidade de um nome referir um objecto em termos de uma cadeia de comunicação que recua até ao próprio objecto, sendo este o principal responsável pelo fenómeno de referir, em particular o objecto é encarado como sendo a sua causa. A função semântica de referir é determinada basicamente em termos do próprio objecto e do carácter social da linguagem e não do conhecimento identificador que permite identificar o objecto (que caracterizava o modelo decritivista). No entanto, apesar de necessária, não aceitamos a cadeia causal como sendo suficiente (ao contrário de Devitt); aceitar a insuficiência, por parte da cadeia causal, para explicar todos os usos de um termo vai ter consequências igualmente importantes para a Teoria do Sentido.

\section{B. TEORIA DO SENTIDO}

A nova teoria, enquanto Teoria do Sentido, i.e., enquanto tendo que dar resposta ao problema de saber o que é o sentido do nome, qual o seu conteúdo ou como é que ele contribui para o sentido das proposições nas quais ocorre (e encarada como complemento à Teoria da Referência), admite a existência de algum ingrediente no sentido de um termo para além de (e que não coincide com) o próprio objecto. Apesar da função semântica de referir ser objecto-dependente, ela não é para ser encarada como coincidindo com o próprio objecto, tal como já atrás fizemos notar ${ }^{19}$. O sentido de um nome

\footnotetext{
${ }^{19} \mathrm{Cf}$. acima, pgs. 12 e 13.
} 
não consiste assim exclusivamente no objecto por ele referido (ao contrário do que Russell - na interpretação fraca - e Kripke ${ }^{20}$ defenderiam).

A Teoria da Referência Directa, segundo a qual o sentido de um nome é para ser identificado exclusivamente com o objecto por ele referido, é assim por nós explicitamente rejeitada. Admiti-la, seria ficar sem solução para problemas semânticos conhecidos como o Puzzle de Frege (ou o problema da verdade de identidades não-triviais, informativas), o Puzzle dos Nomes Vazios ou o Puzzle das Existenciais Negativas Verdadeiras ${ }^{21}$. Foi, de resto, para resolver problemas semânticos deste tipo que Russell foi sendo empurrado para considerar cada vez um menor número de nomes como sendo termos genuinamente referenciais.

Aquele ingrediente, para lá do próprio objecto, que contribui para o sentido de um nome é por nós concebido em termos de informação socialmente disponível e causalmente ligada ao objecto, a qual pode ser elucidada de duas formas não exclusivas: i) como coincidindo com o tipo de cadeia causal que identifica um modo de apresentação do objecto; e ii) como correspondendo a um dossier de informação socialmente disponível e ainda causalmente ligada ao objecto. Vamos então tratar de cada uma destas formas de interpretar o Sinn (se assim lhe pudermos chamar) de um nome separadamente.

Podemos conceber o conjunto de todos os usos de um certo termo como sendo constituído por diversas cadeias causais (com origem no mesmo objecto) de tal maneira que se fique uma rede de usos. Aquilo que é comum a todos os usos do termo (que fazem parte da rede) é a partilha do mesmo modo de apresentação do objecto. Tomando como exemplo os nomes próprios «Hesperus» e «Phosphorus», ao primeiro está associado o facto de o planeta Vénus ser visível ao entardecer, ao segundo, o facto de ele ser visível ao amanhecer. Cada modo de apresentação do planeta Vénus, associado a cada um dos nomes, determina assim uma rede causal diferente. Podemos assim construir uma nova concepção de Sinn de um termo como sendo aquilo que corresponde a um modo de apresentação não-descritivista do objecto, o qual é identificável com a rede causal subjacente a um certo uso desse termo ${ }^{22}$. A grande vantagem que esta concepção de Sinn tem, sobre a concepção tradicional de um Sinn decritivista, é o facto de permitir explicar que um certo uso de um termo refira um objecto mesmo que a ele esteja associado um Sinn que contém informação falsa, massivamente falsa

\footnotetext{
${ }^{20}$ Cf. S. Kripke (1979b).

${ }^{21}$ Cf. A. Silva Graça, Referência e Denotação, pgs. 84 e 85.

${ }^{22}$ Cf. M. Devitt (1987), pg. 74.
} 
ou incompleta acerca do objecto, o que permite escapar aos conhecidos argumentos anti-descritivistas do erro e da ignorância.

Como explicar, seguindo uma teoria de inspiração causal como a que temos vindo a desenvolver, o problema dos nomes vazios? Em particular, como é que nomes como «Pai Natal», «Batman» ou «Ulisses» têm sentido, se a teoria do sentido é considerada como sendo uma extensão da teoria da referência e se a estes nomes não corresponde qualquer objecto que possa estar na base de uma cadeia causal de usos? De facto este tipo de casos merece especial atenção. A partir do momento em que o nome entra na comunidade linguística, o seu sentido e o facto de ele contribuir para o valor de verdade de proposições nas quais ocorre é explicável: de acordo com a nova teoria, são os mecanismos sociais que regulam a comunicação numa comunidade linguística que garantem a explicação desses factos. $\mathrm{O}$ facto de um nome não ter referência não impede que não exista um tipo de cadeia causal subjacente ao seu uso, a qual permite distinguir um nome vazio de um mero ruído. O problema coloca-se então nos primeiros usos do termo, naqueles usos em que se constata uma deficiente ancoragem da cadeia causal. O nome pode ser vazio porque entra na comunidade linguística como o nome de um objecto inexistente que meramente se alucinou ou como o nome de um objecto inexistente que pertence a uma obra de ficção; em todo o caso, a origem da cadeia causal não é standard, o que faz com que a única especificidade que estes nomes têm seja o facto de a rede causal não estar adequadamente fundada no objecto. A falta de fundação adequada da rede no objecto é então aquilo que justifica a existência de nomes vazios e a sua diferença em relação a meros ruídos ininteligíveis.

A segunda forma de entender um Sinn não-descritivista é encará-lo como correspondendo a um dossier de informação ${ }^{23}$ socialmente disponível e também causalmente ligada ao objecto. A ideia é a de interpretar o modo de apresentação do objecto como consistindo numa certa concepção ou forma de pensar acerca do objecto. Na prática, isto equivale a um dossier de informação corrigível, imperfeito e aberto, e não a uma descrição completa, do objecto, e explicitamente resulta de uma reelaboração do conceito de estereotipo, apresentado por Putnam. O conjunto de propriedades aparentes da extensão de um termo (o estereotipo), o qual está ao dispor de todos os utentes de uma língua, é na verdade uma certa forma de pensar acerca da extensão do termo a qual, complementada com a natureza do próprio objecto referido, faz com que seja possível identificar o sentido desse termo ${ }^{24}$.

\footnotetext{
${ }^{23}$ Cf. D. Wiggins (1993).

${ }^{24}$ Cf. H. Putnam (1975).
} 
O Sinn não-descritivista de um termo, em qualquer uma das duas versões apresentadas, distingue-se do Sinn descritivista por identificar o objecto através, não de um conjunto de propriedades a ser satisfeitas por ele e só por ele, mas sim através de uma propriedade de natureza relacional, i.e., através da propriedade de estar causalmente ligado a ele.

\section{CONCLUSÕES}

Saliente-se agora um aspecto interessante: a não aceitação de uma teoria causal pura, que considerasse a cadeia causal como condição suficiente (para além de necessária) da referência, e a não aceitação da Teoria da Referência Directa são ambas um sinal de que é necessário alguma informação acerca do objecto para que o nome refira e tenha sentido. Por outras palavras, a insuficiência por parte da cadeia causal, por um lado, e por parte do objecto, por outro, para explicar, respectivamente, a referência e o sentido de um nome, é apresentada como um sintoma do mesmo problema.

Assim, foi apresentado no ensaio um desenvolvimento desta ideia, entendendo o contacto de Russell como correspondendo à exigência de alguma informação relevante acerca do objecto para o uso competente de um termo. Esta ideia é sugestiva por diversas razões, em particular porque retém o ponto essencial para que o Principle of Acquaintance de Russell chama a atenção. Efectivamente, segundo este princípio russelliano, não há compreensão de uma proposição completamente analisada sem que haja contacto com todos os seus constituintes. De acordo com a nova teoria que acabámos de apresentar, também não há compreensão associada ao uso de um nome que não parta do objecto por ele referido, que não esteja causalmente ligada a ele, a todo o tempo, e que perca alguma vez de vista a ligação com o mundo exterior. O uso competente de um nome identifica assim o objecto que com ele está causalmente conectado e veicula um conteúdo que também está determinado por essa relação causal.

A irredutibilidade das duas funções semânticas referência e denotação, atribuíveis, respectivamente, a nomes e a descrições definidas, pode assim ser obtida a partir de um trabalho de reconstrução dos resultados principais da filosofia de Bertrand Russell, do modo que acabámos de mostrar, trazendo o Principle of Acquaintance como instrumento básico de trabalho.

\section{Adriana Silva Graça}

adrianasg@mail.doc.fl.ul.pt

Faculdade de Letras de Universidade de Lisboa

Departamento de Filosofia

Alameda da Universidade, 1600-214 Lisboa 
REFERÊNCIA E DENOTAÇÃO

\section{Bibliografia}

Boolos, George (org.), Meaning and Method. Essays in Honor of Hilary Putnam, New York, Cambridge University Press, 1990.

Devitt, Michael. "Singular Terms", Journal of Philosophy 71, 1974,183205.

Devitt, Michael. "Critical Notice of Gareth Evans, The Varieties of Reference", Australasian Journal of Philosophy, Vol. 63, No. 2, 1985, 216231.

Devitt, Michael and Kim Sterelny. Language and Reality. An Introduction to the Philosophy of Language, Oxford, Basil Blackwell, 1987. Second Edition: Oxford, Basil Blackwell, 1999.

Devitt, Michael. "Meanings Just Ain't in the Head", in George Boolos (org.), Meaning and Method. Essays in Honor of Hilary Putnam, 79-104.

Devitt, Michael. "Against Direct Reference", Midwest Studies in Philosophy, XIV, 1989, 206-240.

Donnellan, Keith. "Reference and Definite Descriptions", Philosophical Review 75, 1966, 281-304. Reimpresso em S. Schwartz (org.), Naming, Necessity, and Natural Kinds, 42-65. Também reimpresso em Gary Ostertag (org.). Definite Descriptions: A Reader, 173-193.

Donnellan, Keith. "Proper Names and Identifying Descriptions", in Donald Davidson and Gilbert Harman (orgs.), Semantics of Natural Language, Dordrecht, D. Reidel, 1972, 356-379.

Dummett, Michael. Frege: Philosophy of Language. London, Duckworth, 1973. Edição revista, 1981.

Evans, Gareth. "The Causal Theory of Names", Proceedings of the Aristotelian Society, Supp. Vol. 47, 1973, 187-208. Reimpresso em Adrian W. Moore (orgs.), Meaning and Reference, 208-227.

Evans, Gareth. The Varieties of Reference, edited by John McDowell, New York and Oxford, Oxford University Press, 1982.

Frege, Gottlob. "Über Sinn und Bedeutung", Zeitschrift für Philosophie und Philosophische Kritik 100, 1892, 25-50. Tradução inglesa de Max Black: «On Sense and Reference», in Peter Geach and Max Black (orgs.), Translations from the Philosophical Writings of Gottlob Frege, Oxford, Basil Blackwell, 1952, 56-78. Reimpresso em A. Moore (org.), Meaning and Reference, 23-42. Tradução inglesa de M. Black, V. H. Dudman, P. Geach, H, Kaal, E.-H. W. Kluge, B. McGuinness, and R. H. Stoothoff: "On Sense and Meaning", in Brian McGuinness (org.), Collected Papers on Mathematics, Logic, and Philosophy, Oxford, Basil Blackwell, 1984, 157-77. 
Grice, H. P. "Vacuous Names", in Donald Davidson and Jaakko Hintikka (orgs.), Words and Objections, Amsterdam, Kluwer, 1969, 138-144.

Kripke, Saul. "Naming and Necessity", in Donald Davidson and Gilbert Harman (orgs.), Semantics of Natural Language, Dordrecht, D. Reidel, 1972, 253-355, 763-769. Reimpresso, com um Prefácio, como Naming and Necessity, Cambridge, Mass., Harvard University Press, 1980 e Oxford, Basil Blackwell, 1980.

Kripke, Saul. "Speaker's Reference and Semantic Reference", in P. French, T.Uehling, and H. Wettstein (orgs.), Contemporary Perspectives in the Philosophy of Language, Minneapolis, University of Minnesota Press, 1979, 6-27. Reimpresso em Gary Ostertag (org.), Definite Descriptions: A Reader, 225-256.

Kripke, Saul. "A Puzzle about Belief”, in A. Margalit (org.), Meaning and Use, Dordrecht, D. Reidel, 1979, 239-283.

McDowell, John. "On the Sense and Reference of a Proper Name", Mind 86, 1977, 159-185. Reimpresso em A. W. Moore (org.), Meaning and Reference, 111-136.

Moore, Adrian W. (org.). Meaning and Reference, Oxford and New York, Oxford University Press, 1993.

Neale, Stephen. Descriptions, Cambridge, Mass., The MIT Press, 1990.

Putnam, Hilary. "The Meaning of Meaning", in K. Gunderson (org.), Minnesota Studies in the Philosophy of Science, Vol VII: Language, Mind, and Knowledge, Minneapolis, University of Minnesota Press, 1975. Reimpresso em Hilary Putnam, Philosophical Papers, Vol 2: Mind, Language, and Reality, 215-271.

Russell, Bertrand. "On Denoting", Mind 14, 1905, 479-493. Reimpresso em Bertrand Russell, Logic and Knowledge, 41-56.

Russell, Bertrand. "Knowledge by Acquaintance and Knowledge by Description", Proceedings of the Aristotelian Society 11, 1911, 108-128. Reimpresso em Bertrand Russell, Mysticism and Logic, London, George Allen and Unwin, 1917.

Russell, Bertrand. "On the Relation of Sense Data to Physics", reimpresso em Reimpresso em Bertrand Russell, Mysticism and Logic, London, George Allen and Unwin, 1917.

Russell, Bertrand. The Problems of Philosophy. New York, Oxford University Press, 1917.

Russell, Bertrand. "My Mental Development", in Paul Arthur Schilpp (org.), The Philosophy of Bertrand Russell, Evanston, Illinois, Northwestern University Press, 1944.

Russell, Bertrand. Logic and Knowledge, edited by R. C. Marsh, London, George Allen and Unwin, 1956. 
Russell, Bertrand. "Mr. Strawson on Referring", Mind 66, 1956, 385-389.

Russell, Bertrand. My Philosophical Development, London, George Allen and Unwin, 1959.

Russell, Bertrand. The Philosophy of Logical Atomism, edited by David Pears, La Salle, Illinois, Open Court, 1985. Também em Bertrand Russell, Logic and Knowledge, 177-281. (Primeira Publicação em 1918).

Sainsbury, R. M. Russell, London, Routledge and Kegan Paul, 1979.

Strawson, Peter F. "On Referring", Mind 59, 1950, 320-44. Reimpresso em A. W. Moore (org.), Meaning and Reference, 56-79. Também reimpresso em Gary Ostertag (org.), Definite Descriptions: A Reader, 135-160.

Wiggins, David. "Putnam's Doctrine of Natural Kind Words and Frege's Doctrines of Sense, Reference, and Extensions: Can They Cohere?", Revue de Théologie et de Philosophie, 1993/3. Reimpresso em A. W. Moore (org.), Meaning and Reference, 192-207. 